\title{
Wind-Induced Dynamic Failure Mechanism and Equivalent Static Wind Load of Single- Layer Latticed Barrel Vaults
}

\author{
Junlin Wang, Hua Guo, Hongmei Li, Chengyang Dun, Jianheng Sun*
}

Hebei Agricultural University, Baoding 071001, China

Corresponding Author Email: sjh@ hebau.edu.cn

https://doi.org/10.18280/ijht.380217

Received: 8 January 2020

Accepted: 15 March 2020

\section{Keywords:}

latticed barrel vault structure, wind load, critical load coefficient, equivalent static wind load (ESWL), dynamic failure mode

\begin{abstract}
This paper simplifies the analysis of equivalent static wind load (ESWL) based on dynamic failures, aiming to promote the design of strong, stable, and wind-resistant latticed barrel vaults. The static and dynamic responses of multiple latticed barrel vaults in elastic, plastic, and elastoplastic states were analyzed separately under wind load. Then, the BudianskyRoth criterion and the Hsu S.C. criterion were combined to compute the dynamic failure critical load (DFCL) of latticed shell. Through conceptual analysis and quantitative calculation, three dynamic failure modes were summarized for latticed barrel vaults under wind load, namely, elastic dynamic instability failure, elastoplastic dynamic instability failure, and plastic dynamic strength failure. After that, the authors determined the relationship between the static load and DFCL of latticed shell, and relied on it to establish the equivalent static wind load based on dynamic failure. The research results provide a good reference for the wind-resistant design of single-layer latticed barrel vaults.
\end{abstract}

\section{INTRODUCTION}

Large-span space structure is highly sensitive to wind load, owing to its light weight, high flexibility, small damping, and low natural vibration frequency. The wind sensitivity of such structure is increasing with the growing span and use of lightweight materials. The latticed shell is an important component in large-space space structure. The wind-resistant design and long-term use of latticed shell is challenged by its obvious dynamic response to wind load. If the response is large and continuous, the latticed shell might suffer dynamic failure or fatigue damage, endangering the structural safety [1].

The wind load is very different from seismic action. The magnitude of ground motion is generally not affected by geometric parameters, namely, the rise-span ratio of latticed shell. By contrast, the magnitude and distribution of wind load, as well as the wind-induced dynamic failure mode, vary with the geometries and stiffnesses of latticed shell. As a result, it is very complex to analyze the wind-induced dynamic failure of latticed shell $[2,3]$. It is urgently needed to simplify the complex problem of wind-induced dynamic failure of latticed shell into a static analysis problem, which is easier to be solved by engineers, and facilitate the wind resistance design of latticed shell.

Many scholars have explored the dynamic response, dynamic stability, failure mechanism, failure mode, and simplified analysis method of latticed shell under seismic action. However, there are much fewer reports on the nonlinear dynamic response, failure mechanism, failure mode, and simplified analysis method of latticed shell under wind load [4-10]. For example, Li et al. analyzed the nonlinear dynamic response and dynamic stability of K6 single-layer spherical latticed shell under wind load, using the wind pressure distribution coefficient measured in wind tunnel test $[11,12]$. Through wind tunnel test and numerical simulation,
Uematsu et al. [13] studied the dominant vibration modes of wind-induced dynamic response of a $120 \mathrm{~m}$-span single-layer spherical latticed shell. Targeting a single-layer cylindrical latticed shell, Zhou and Gu [14] obtained the shape coefficient of wind load by wind tunnel test, numerically simulated the dynamic response at different wind directions, and determined the critical wind speed at each wind direction under the Budiansky-Roth criterion. Using finite particle method, Yu et al. [15] examined the collapse performance of a double-layer cylindrical latticed shell under strong wind, established the control index for performance measurement, and optimized the structural parameters for collapse resistance. Wang et al. investigated the process of the elastoplastic dynamic failure of a single-layer latticed shell under wind load and snow load, under different structural forms, geometries, and supports [16, 17]. Considering the negative impacts of fluctuating wind on structure stability, Uematsu et al. [18] identified the distribution of equivalent static wind load (ESWL) on latticed shell through stability analysis, which greatly simplifies the estimation of that distribution on single-layer latticed shells. Li et al. [19] conducted finite-element analysis on the dynamic response of single-layer latticed domes, and designed a simple estimation model for the design wind load of these domes. Fenerci et al. probed into the dynamic response and dynamic failure of long-span spatial structures, and calculated the ESWLs from displacement, internal force, and stability, respectively [20, 21].

Overall, there are two main problems with the existing studies on wind-induced dynamic response of latticed shells: (1) Most studies have focused on the wind-induced dynamic instability failure of a latticed shell structure, failing to clarify the exact failure mode. Under wind load, a latticed shell could suffer three kinds of dynamic failures: elastic dynamic instability failure as the latticed shell is in elastic state; elastoplastic dynamic instability failure as some members 
enter the plastic state; plastic dynamic strength failure as the entire shell enters the plastic state. The failure mode needs to be identified based on the dynamic failure features of the latticed shell under wind load.

(2) The ESWL is either estimated by a simple model in the linear elastic range, or calculated from displacement, internal force, and stability. The calculation formulas based on displacement or internal force take no account of the stability requirement. Some scholars may have judged the dynamic instability from ESWL, but did not specify the type of dynamic instability. Therefore, it is difficult to design a strong and stable latticed shell by the methods proposed in the previous studies.

This paper aims to simplify the complex wind-induced dynamic failure of latticed shell into an equivalent problem under static wind load. To this end, an ESWL analysis method was proposed based on dynamic failure, involving all three possible failure modes of latticed shell under wind load. Specifically, the finite-element analysis software ANSYS was introduced to analyze the whole process of elastoplastic dynamic failure of single-layer latticed barrel vaults under wind load. Next, Budiansky-Roth criterion [22] and Hsu S.C. criterion [23] were combined to compute the dynamic failure critical load (DFCL) of latticed shell in an accurate and effective manner. On this basis, the authors investigated the modes and influencing factors of dynamic failures of latticed shell under wind load, and simplified the analysis of ESWL for that structure.

\section{DYNAMIC FAILURE ANALYSIS}

\subsection{Wind load simulation}

The wind load was simulated on MATLAB through autoregressive (AR) modelling. The simulation parameters were configured as follows: the average wind speed was assumed to obey the exponential law; the Davenport's fluctuating wind speed spectrum was selected as the target spectrum; the standard wind speed at the height of $10 \mathrm{~m}$ was set to $21.6 \mathrm{~m} / \mathrm{s}$; the regression order, frequency range, frequency increment, time step, simulation time, and surface roughness were set to $4,0.01-10 \mathrm{~Hz}, 0.01 \mathrm{~Hz}, 0.1 \mathrm{~s}, 60 \mathrm{~s}$, and 0.03 , respectively; the attenuation coefficients $C_{x}, C_{y}$ and $C_{z}$ were set to 16,8 and 10 , respectively.

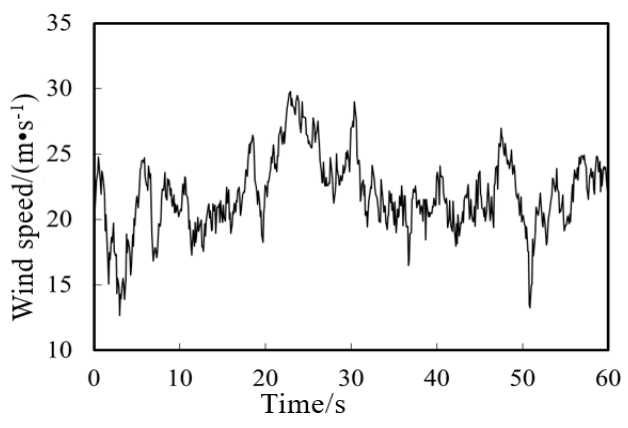

Figure 1. Time history of wind speed at a node

Considering the structural symmetry of the latticed barrel vault, the wind analysis only targets the negative direction of $\mathrm{Y}$ axis. The fluctuating wind speed was simulated by the AR in the light of the spatial correlation between different nodes. The average wind speeds of the nodes were basically the same.
Figure 1 shows the time history of wind speed at a node of the latticed shell. It can be seen that the simulated power spectrum agreed well with the objective function, indicating that the AR is a suitable simulation method for the fluctuating wind speed at each node in the long-span latticed shell [16]

\subsection{Dynamic equation}

For an m-node single-layer latticed shell, the dynamic equilibrium differential equation can be expressed as:

$$
\boldsymbol{M} \ddot{\boldsymbol{u}}(t)+\boldsymbol{C} \dot{\boldsymbol{u}}(t)+\boldsymbol{K u}(t)=\boldsymbol{F}(t)
$$

where, $\boldsymbol{M}, \boldsymbol{C}$ and $\boldsymbol{K}$ are the mass matrix, damping matrix, and stiffness matrix of the structure, respectively; $\boldsymbol{u}(t)$ is the displacement matrix; $\boldsymbol{F}(t)$ is the wind load matrix.

The wind load on each node of the latticed shell can be described as:

$$
\begin{aligned}
& \boldsymbol{F}_{i}(t)=\left\{\begin{array}{lllllll}
c_{x i} F_{i}(t) & c_{y i} F_{i}(t) & c_{z i} F_{i}(t) & 0 & 0 & 0
\end{array}\right\}^{\mathrm{T}} \\
& F_{i}(t)=\lambda F_{i, 0}(t)
\end{aligned}
$$

where, $c_{x i}, c_{y i}$ and $c_{z i}$ are the direction cosines of the global coordinate axes $\mathrm{x}, \mathrm{y}$ and $\mathrm{z}$, respectively; $F_{i}(t)$ is the wind load on the latticed shell; $\lambda$ is the dimensionless load coefficient; $F_{i, 0}(t)$ is the initial wind load on the latticed shell, which can be derived from the basic wind pressure:

$$
F_{i, 0}(t)=\mu_{z i} \mu_{s i} w_{i}(t) A_{i}
$$

where, $\mu_{z i}$ is the height variation coefficient of wind pressure at node $i ; \mu_{s i}$ is the shape coefficient of wind load at node $i ; A_{i}$ is the equivalent wind area at node $i ; w_{i}(t)$ is the basic wind pressure at node $i$, which can be transformed from the basic wind speed by Bernoulli's equation:

$$
w_{i}(t)=\rho\left(\bar{v}_{i}+v_{i}(t)\right)^{2} / 2
$$

where, $\rho$ is the air density; $\bar{v}_{i}$ is the average wind speed; $v_{i}(t)$ is the fluctuating wind speed.

\subsection{Dynamic failure criterion}

Dynamic failure criterion is the key to determining the DFCL of large complex structures like latticed shell. This paper combines the Budiansky-Roth criterion with the Hsu S.C. criterion into a new criterion to identify the dynamic failure modes of latticed barrel vaults in elastic, plastic, and elastoplastic states under wind load.

According to Budiansky-Roth criterion, the DFCL of a structure is the load that causes sudden changes to the structure response. This criterion is applicable to the cases with an unstable post-failure load-displacement curve, and capable of computing the accurate critical load of latticed shell (Figure 2a). However, if the post-failure load-displacement curve is stable (Figure 2b), the Budiansky-Roth criterion cannot be directly applied, but coupled with the Hsu S.C. criterion. The Hsu S.C. criterion holds that, at the critical load, the loaddisplacement curve of the structure will oscillate about or deviate from the initial equilibrium position, revealing the upper and lower bounds of the critical load. 


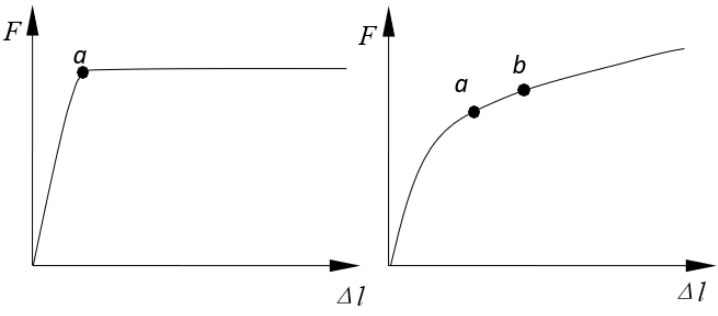

Figure 2. Load-displacement curves under Budiansky-Roth criterion and Hsu S.C. criterion

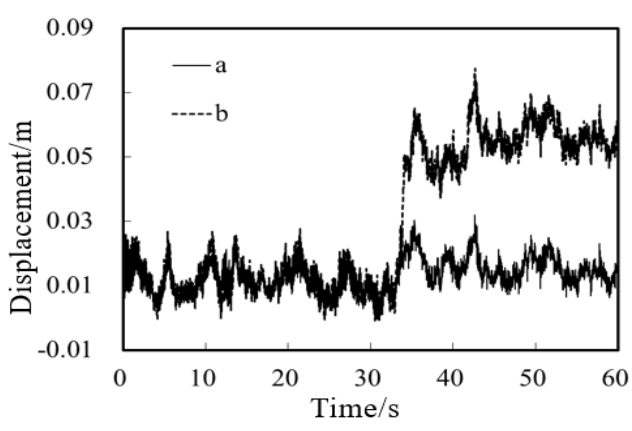

Figure 3. Time history of node displacement under our criterion

Here, the two criteria are fully combined to judge the DFCL of latticed shell. Under the combined criterion, the critical load is defined as the load that causes the time history of node displacement to deviate from the initial equilibrium position (Figure 3).

\section{DYNAMIC FAILURE MECHANISM OF LATTICED SHELL}

\subsection{Finite-element model}

As shown in Figure 4, the latticed barrel vault was meshed into three-way grids, without changing the wave width B. The members were simulated as BEAM188 elements in ANSYS. Meanwhile, the roof load and the dead weight of the barrel vault were simulated as MASS2 1 elements, and distributed to each node on the structure. The design parameters and analysis parameters of the latticed shell are listed in Tables 1 and 2, respectively.

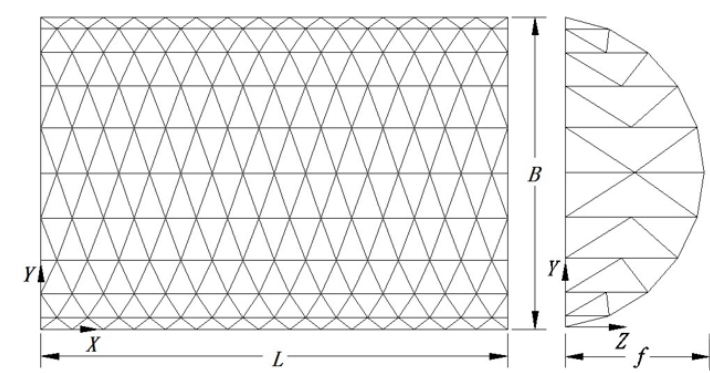

Figure 4. Structure of single-layer latticed barrel vault

Table 1. Design parameters

\begin{tabular}{cccccc}
\hline Latticed barrel vault & Wave width $\boldsymbol{B} / \mathbf{m}$ & Rod size $/ \mathbf{m m}$ & $\mathbf{L o a d} /\left(\mathbf{k N} \cdot \mathbf{m}^{-\mathbf{2}}\right)$ & Materials & Support pattern \\
\hline Three-way grids & 30 & $121 \times 8$ & 1.0 & $\mathrm{Q} 235$ & Three-way fixed connection \\
\hline
\end{tabular}

Table 2. Analysis parameters

\begin{tabular}{cccccc}
\hline Yield Strength $/ \mathbf{M P a}$ & Density $/\left(\mathrm{kg}^{\cdot} \mathbf{m}^{-3}\right)$ & Elastic modulus/MPa & Poisson's ratio & Yield criterion & Strengthening criteria \\
\hline 235 & 7,850 & $2.1 \times 10^{5}$ & 0.26 & Von Mises & BISO \\
\hline
\end{tabular}

\subsection{Analysis on numerical results}

Let $R(n, t)$ be the response of a member in latticed barrel vault at time $\mathrm{t}$ under the wind load $F(\mathrm{t})$. The characteristic response of the structure equals to maximum response of each member in a complete calculation cycle:

$$
R_{\max }(N, T)=\max _{0 \leqslant n \leqslant N}\left[\max _{0 \leqslant t \leqslant T} R(n, t)\right]
$$

where, $N$ is the total number of members in the structure, $n \leq N$; $T$ is a complete calculation cycle, $t \leq T$.

On this basis, the incremental dynamic analysis (IDA) was performed with the initial wind load being that corresponding to the basic wind pressure. Note that the power spectrum of the wind load is normalized. If the amplitude of wind speeds in the same set changes proportionally, the corresponding dimensional power spectrum and time will be stretched (or compressed).

For simplicity, the wind load level was increased continuously through proportional adjustment of the load coefficient [16]. Then, the nonlinear dynamic response of the structure was calculated under various wind loads. On this basis, the critical failure coefficient of the structure was determined by the combined criterion.

Figure 5 shows the curve between load coefficient and displacement (load-displacement curve) of the single-layer latticed barrel vault with the longitudinal length $\mathrm{L}$ of $45 \mathrm{~m}$ and the rise-span ratio f/B of 0.45. Like type I in Figure 2, the loaddisplacement curve has obvious critical feature points, indicating that the critical load coefficient can be directly judged by Budiansky-Roth criterion. On the loaddisplacement curve, when the load factor $\lambda$ increased slightly from 6.67 , the structure displacement grew rapidly. Hence, $\lambda=6.67$ is the DFCL of the structure.

Figure 6 shows the load-displacement curve of the singlelayer latticed barrel vault with the longitudinal length $\mathrm{L}$ of $45 \mathrm{~m}$ and the rise-span ratio $\mathrm{f} / \mathrm{B}$ of 0.15 . Like type II in Figure 2, the load-displacement curve has no obvious critical feature point, indicating that the critical load coefficient should be judged by the combined criterion. On the load-displacement curve, the load coefficient was 42.56 for point a and 44.16 for point $b$.

As shown in Figure 7, the time history of displacement for point $b$ clearly deviated from the initial equilibrium position. Hence, the load coefficient (44.1) for point b was considered the DFCL of the structure. 


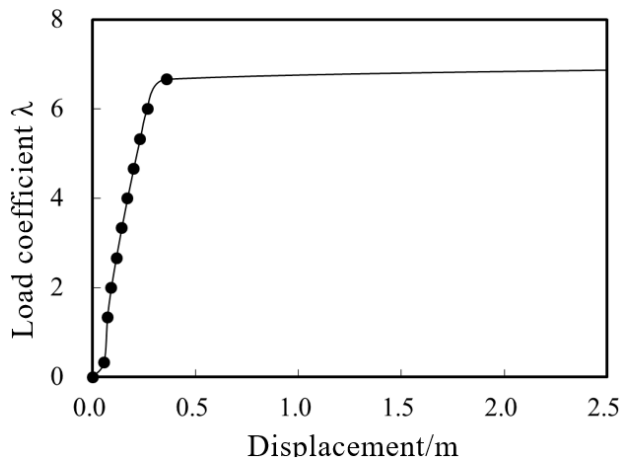

Figure 5. Load displacement curve at $\mathrm{L}=45 \mathrm{~m}$ and $\mathrm{f} / \mathrm{B}=0.45$

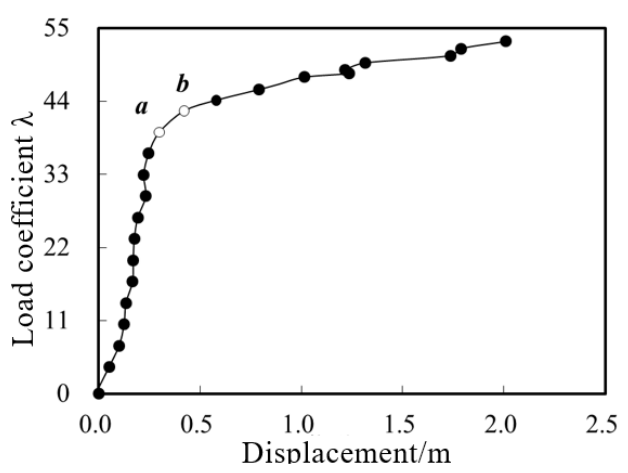

Figure 6. $\mathrm{Load}$ displacement curve at $\mathrm{L}=45 \mathrm{~m}$ and $\mathrm{f} / \mathrm{B}=0.15$

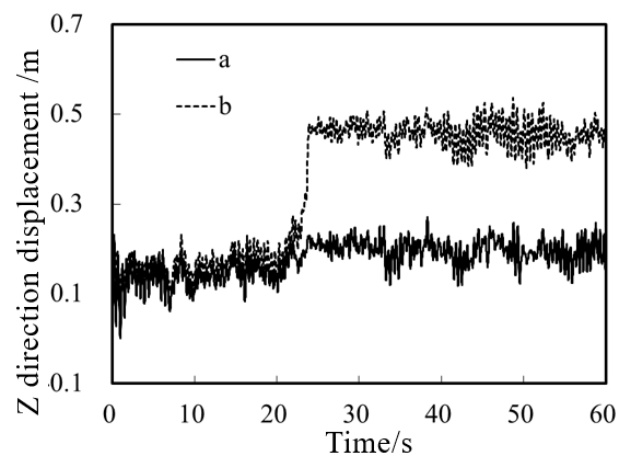

Figure 7. Time history of displacement for points $a$ and $b$ of type II in Figure 2

\subsection{Wind-induced dynamic failure mode}

Dynamic failure means the latticed shell suddenly changes from the initial configuration to a deformation form under wind load. Under dynamic failure, the whole or part of the structure jump from the initial equilibrium position, exhibiting a large displacement from that position. Therefore, the failure mode of the latticed shell can be judged from the change trend of displacement response.

Through conceptual analysis and quantitative calculation, the dynamic failure modes of single-layer latticed barrel vaults with $\mathrm{L}=45 \mathrm{~m}$ and $\mathrm{f} / \mathrm{B}$ of $0.15,0.25$, and 0.45 were derived from their dynamic response process induced by wind. Figures 8-10 illustrate the elastic dynamic failure mode, the elastoplastic dynamic failure mode and the plastic dynamic strength failure mode, respectively.

When the rise-span ratio f/B is 0.45 , the single-layer latticed barrel vault is mainly subjected to the wind pressure on the windward side. Conceptual analysis shows that the structure might suffer dynamic instability. As shown in Figure 8, at the load coefficient $\lambda=5.33$, some members of the structure started to enter the plastic state; at the load coefficient $\lambda=6.67$ (i.e. before the dynamic failure), about $15.92 \%$ of all members fully or partially entered the plastic state, but only $1.02 \%$ of all members were fully plastic; at the load coefficient $\lambda=7.00$, the entire structure saddened sagged down and collapsed on the windward side. Before that, the structure maintained the initial state, showing no weakening of overall stiffness. The failure process carries obvious features of dynamic instability. The results show that elastic deformation is the dominant mode in the critical state of dynamic failure. Therefore, it is concluded that the failure mode of the latticed shell bears the features of elastic dynamic instability.

When the rise-span ratio $\mathrm{f} / \mathrm{B}$ is 0.25 , the single-layer latticed barrel vault is mainly subjected to the wind suction on the windward side, and partially to wind pressure. Conceptual analysis shows that the structure might suffer dynamic instability. As shown in Figure 9, at the load coefficient $\lambda=12.85$, about $20.81 \%$ of all members fully or partially entered the plastic state, but only $1.02 \%$ of all members were fully plastic; at the load coefficient $\lambda=14.99$ (i.e. before the dynamic failure), $45.31 \%$ of all members fully or partially entered the plastic state, but only $16.12 \%$ were fully plastic; at the load coefficient $\lambda=16.06$, the windward surface of the latticed shell suddenly sagged down and collapsed. Before that, the structure exhibited a slight variation in shape, and its overall stiffness slightly weakened due to the plastic development. The failure process carries some features of dynamic instability. The results show that, to some extent, the structure went through plastic development at the critical state of dynamic failure, and generally belonged to the elastoplastic state. Therefore, it is concluded that the failure mode of the latticed shell is elastoplastic dynamic instability.

When the rise-span ratio $\mathrm{f} / \mathrm{B}$ is 0.15 , the single-layer latticed barrel vault is mainly subjected to wind suction, and each member is under tension. Conceptual analysis shows that the structure might undergo plastic dynamic strength failure. As shown in Figure 10, at the load coefficient $\lambda=44.16$ (i.e. before the dynamic failure), $81.43 \%$ of all members fully or partially entered the plastic state, and $72.45 \%$ were fully plastic. In this case, the plasticity of the latticed shell had developed deeply and comprehensively. At the load coefficient $\lambda=48.18$, the windward surface of the structure suddenly bulged and failed locally. Before that, the structure shape changed gradually, and its overall stiffness was obviously weakened, owing to the full development of plasticity. The failure process carries significant features of dynamic strength failure. The results show that the structure went through sufficient plastic development in the critical state of dynamic failure, and belonged to the plastic state. Therefore, it is concluded that the failure mode of the structure is plastic dynamic strength failure.

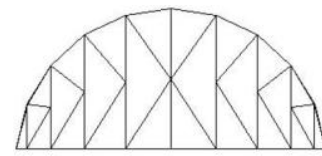

(a) $\lambda=5.33$

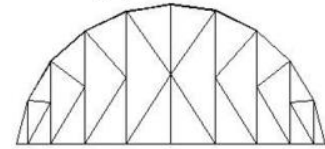

(c) $\lambda=6.67$

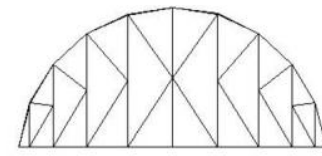

(b) $\lambda=6.00$

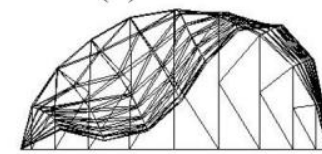

(d) $\lambda=7.00$
Figure 8. Failure mode of elastic dynamic instability 


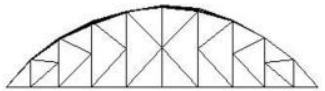

(a) $\lambda=12.85$

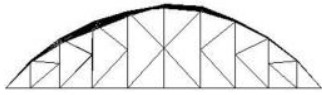

(c) $\lambda=14.99$

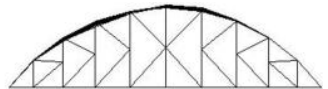

(b) $\lambda=13.92$

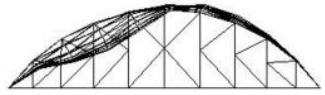

(d) $\lambda=16.06$
Figure 9. Failure mode of elastoplastic dynamic instability

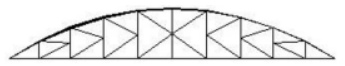

(a) $\lambda=26.77$

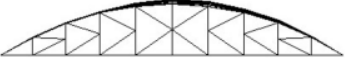

(c) $\lambda=44.16$

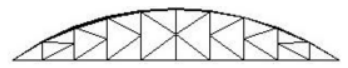

(b) $\lambda=42.56$

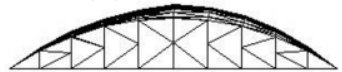

(d) $\lambda=48.18$
Figure 10. Failure mode of plastic dynamic strength instability

\section{SIMPLIFIED ANALYSIS ON ESWL}

Let $\alpha$ be the influence coefficient of dynamic effect, which equals the critical coefficient ratio of dynamic failure to static failure. Then, the ESWL of dynamic failure can be calculated by:

$$
\hat{F}=\alpha \bar{F}
$$

where, $\bar{F}$ is the dynamic wind load of the latticed shell.

Then, an IDA was performed to analyze the wind-induced dynamic responses of single-layer latticed barrel vaults with $\mathrm{L}=45 \mathrm{~m}$ and $\mathrm{f} / \mathrm{B}$ of $0.15,0.25,0.35$ and 0.45 , respectively. Through the analysis, the critical coefficients of dynamic failure were determined. Similarly, nonlinear static failure analysis was conducted on the same structures under wind load, to determine the critical coefficients of static failure. The critical coefficients thus obtained are listed in Table 3. The linear regression curves of these structures are presented in Figure 11.

Table 3. Static and dynamic critical load coefficients at different $\mathrm{f} / \mathrm{B}$ values

\begin{tabular}{ccccc}
\hline Rise-span ratio & 0.15 & 0.25 & 0.35 & 0.45 \\
\hline Dynamic & 44.16 & 14.99 & 9.90 & 6.67 \\
Static & 75.76 & 27.10 & 20.29 & 13.12 \\
\hline
\end{tabular}

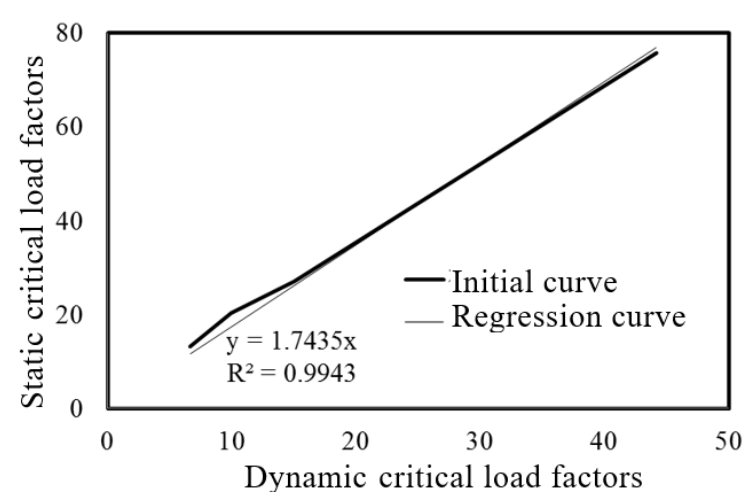

Figure 11. Linear regression curves at different f/B values
The R square of linear regression was 0.994 , and the Fstatistics was 0.000 , smaller than $\alpha=0.05$. Thus, the ESWL of single-layer latticed barrel vault in dynamic failure was obtained as $\hat{F}=1.74 \bar{F}$.

Another IDA was performed to analyze the wind-induced dynamic responses of single-layer latticed barrel vaults with $\mathrm{f} / \mathrm{B}=0.25$, and $\mathrm{L}$ of $30 \mathrm{~m}, 45 \mathrm{~m}$, and $60 \mathrm{~m}$, respectively. Through the analysis, the critical coefficients of dynamic failure were determined. Similarly, nonlinear static failure analysis was conducted on the same structures under wind load, to determine the critical coefficients of static failure. The critical coefficients thus obtained are listed in Table 4. The linear regression curves of these structures are presented in Figure 12 .

Table 4. Static and dynamic critical load coefficients at different length-width ratios

\begin{tabular}{ccccc}
\hline Length-width ratio & $\mathbf{1 . 0}$ & $\mathbf{1 . 5}$ & $\mathbf{2 . 0}$ & $\mathbf{2 . 5}$ \\
\hline Dynamic & 21.08 & 14.99 & 11.91 & 8.26 \\
Static & 35.99 & 27.10 & 20.83 & 18.07 \\
\hline
\end{tabular}

The $\mathrm{R}$ square of linear regression was 0.926 , and the Fstatistics was 0.000 , smaller than $\alpha=0.05$. Thus, the ESWL of single-layer latticed barrel vault in dynamic failure was obtained as $\hat{F}=1.78 \bar{F}$.

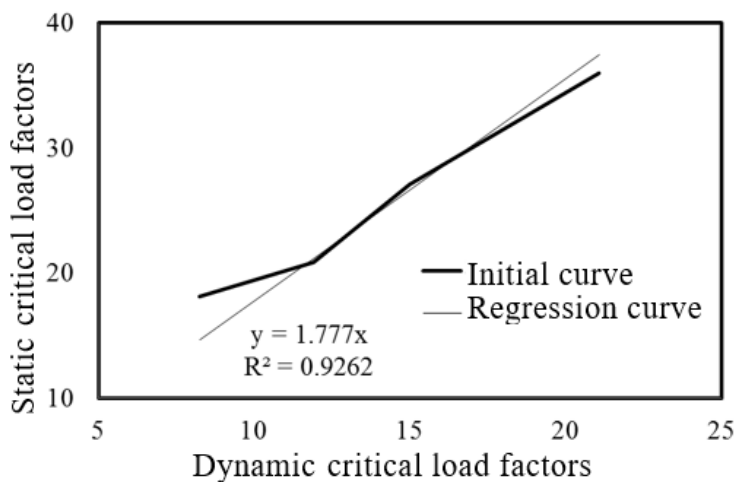

Figure 12. Linear regression curves at different length-width ratios

\section{CONCLUSIONS}

This paper meshes a single-layer latticed barrel vault into three-way grids, and explores the process and features of its dynamic failure under wind load. Moreover, the ESWL analysis was simplified based on dynamic failure, and used to evaluate the failure performance of the structure under static wind load. The main conclusions are as follows:

(1) The Budiansky-Roth criterion is deficient in judging dynamic failure. To overcome the defect, the criterion was combined with Hsu S.C. criterion into a new criterion, which can handle the cases with a stable or unstable post-failure loaddisplacement curve. Then, the new criterion was applied to determine the DFCL of the latticed shell under wind load.

(2) Through conceptual analysis and quantitative calculation, three kinds of wind-induced failure modes of single-layer latticed barrel vaults under wind load were summarized, namely, elastic dynamic instability failure, elastoplastic dynamic instability failure, and plastic dynamic 
strength failure. The features of these failure modes were discriminated in details.

(3) The ESWL based on dynamic failure simultaneously meets the strength and stability requirements of wind-resistant design of latticed shell. The ESWL analysis was simplified based on dynamic failure. Through the analysis, the ESWLs of the structure were calculated as $\hat{F}=1.74 \bar{F}$ and $\hat{F}=1.78 \bar{F}$, respectively, at different rise-span ratios and length-width ratios. The results provide a good reference for the windresistant design of latticed barrel vaults.

\section{ACKNOWLEDGEMENTS}

The author(s) disclosed receipt of the following financial support for the research, authorship, and/or publication of this article: This work was supported by Natural Fund of Hebei Province (Grant No.: E2018204019), Education Youth Fund of Hebei Provincial Education Department (Grant No.: QN2018256) and Science and Engineering Fund of Hebei Agricultural University (Grant No.: LG201713 and ZD201704 ).

\section{REFERENCES}

[1] Yang, Q., Chen, B., Wu, Y., Tamura, Y. (2013). Windinduced response and equivalent static wind load of longspan roof structures by combined Ritz-proper orthogonal decomposition method. Journal of Structural Engineering, 139(6): 997-1008. https://doi.org/10.1061/(ASCE)ST.1943-541X.0000715

[2] Horr, A.M., Safi, M., Alavinasab, S.A. (2003). Computational wind tunnel analyses for large domes using CFD theory. International Journal of Space Structures, 18(2): 85-104. https://doi.org/10.1260/026635103769518206

[3] Uematsu, Y., Tsuruishi, R. (2008). Wind load evaluation system for the design of roof cladding of spherical domes. Journal of Wind Engineering and Industrial Aerodynamics, $\quad$ 96(10-11): 2054-2066. https://doi.org/10.1016/j.jweia.2008.02.051

[4] Jung, H.M., Yoon, S.H., Lee, D.W. (2016). Reinforcement effects of buckling member for singlelayer latticed dome. Journal of the Korean Association for Spatial Structures, 16(4): 45-52. https://doi.org/10.9712/KASS.2016.16.4.045

[5] López, A., Puente, I., Serna, M.A. (2007). Direct evaluation of the buckling loads of semi-rigidly jointed single-layer latticed domes under symmetric loading. Engineering Structures, 29(1): 101-109. https://doi.org/10.1016/j.engstruct.2006.04.008

[6] Kato, S., Yamauchi, Y., Ueki, T. (2005). Buckling load of elliptic paraboloidal single layer reticulated roofs under uniform load. International Journal of Space Structures, 20(2): 91-106. https://doi.org/10.1260/0266351054764227

[7] Moghaddam, H.A. (2000). Seismic behaviour of space structures. International Journal of Space Structures, 15(2):

119-135. https://doi.org/10.1260/0266351001495026

[8] Sadeghi, A. (2004). Horizontal earthquake loading and linear/nonlinear seismic behaviour of double layer barrel vaults. International Journal of Space Structures, 19(1):
21-37. https://doi.org/10.1260/026635104322988344

[9] Kato, S., Ueki, T., Mukaiyama, Y. (1997). Study of dynamic collapse of single layer reticular domes subjected to earthquake motion and the estimation of statically equivalent seismic forces. International Journal of Space Structures, 12(3-4): 191-203. https://doi.org/10.1177/026635119701200308

[10] Kato, S., Ueki, T., Nakazawa, S. (2006). Estimation of buckling loads of elliptic paraboloidal single layer lattice domes under vertical loads. International Journal of Space Structures, 21(4): 173-182. https://doi.org/10.1260/026635106780866006

[11] Li, Y.Q., Tamura, Y. (2004). Wind-resistant analysis for large-span single-layer reticulated shells. International Journal of Space Structures, 19(1): 47-59. https://doi.org/10.1260/026635104322988362

[12] Li, Y.Q., Tamura, Y. (2005). Nonlinear dynamic analysis for large-span single-layer reticulated shells subjected to wind loading. Wind and Structures, 8(1): 35-48. https://doi.org/10.12989/was.2005.8.1.035

[13] Uematsu, Y., Yamada, M., Inoue, A., Hongo, T. (1997). Wind loads and wind-induced dynamic behavior of a single-layer latticed dome. Journal of Wind Engineering and Industrial Aerodynamics, 66(3): 227-248. https://doi.org/10.1016/S0167-6105(97)00133-5

[14] Zhou, X., Gu, M. (2010). An approximation method for computing the dynamic responses and equivalent static wind loads of large-span roof structures. International Journal of Structural Stability and Dynamics, 10(05): 1141-1165. https://doi.org/10.1142/S0219455410003944

[15] Yu, Y., Wang, J.Z., Zhu, X.Y. (2015). Collapse analysis of double-layer cylindrical reticulated shell under strong wind based on finite particle method. Journal of Southeast University, 45(4): 756-762. https://doi.org/10.3969/j.issn.1001-0505.2015.04.025

[16] Wang, J.L., Lu, W., Dun, C.Y., Guo, H., Sun, J.S. (2020). Influence of snow load distribution on the stability of single-layer reticulated shells. International Journal of Safety and Security Engineering, 10(1): 141-147. https://doi.org/10.18280/ijsse.100118

[17] Wang, J.L., Li, H.M., Guo, H., Ren, X.Q., Sun, J.H. (2013). Study on the elastoplastic dynamic failure of single-layer cylindrical reticulated shell structures under wind loads. Applied Mechanics and Materials, 368: 1571-1577.

https://doi.org/10.4028/www.scientific.net/AMM.368370.1571

[18] Uematsu, Y., Sone, T., Yamada, M., Hongo, T. (2002). Wind-induced dynamic response and its load estimation for structural frames of single-layer latticed domes with long spans. Wind and Structures, 5(6): 543-562. https://doi.org/10.12989/was.2002.5.6.543

[19] Li, Y.Q., Tamura, Y., Yoshida, A., Katsumura, A., Cho, K. (2006). Wind loading and its effects on single-layer reticulated cylindrical shells. Journal of Wind Engineering and Industrial Aerodynamics, 94(12): 949973. https://doi.org/10.1016/j.jweia.2006.04.004

[20] Fenerci, A., Øiseth, O. (2018). Strong wind characteristics and dynamic response of a long-span suspension bridge during a storm. Journal of Wind Engineering and Industrial Aerodynamics, 172: 116-138. https://doi.org/10.1016/j.jweia.2017.10.030

[21] Gu, M., Huang, Y. (2015). Equivalent static wind loads 
for stability design of large span roof structures. Wind and $\quad$ Structures, 20(1): 95-115. http://dx.doi.org/10.12989/was.2015.20.1.095

[22] Budiansky, B. (1962). Axisymmetric dynamic buckling of clamped shallow spherical shells. NASA TN, 1510: 597-606.
[23] Hsu, C.S. (1966). On dynamic stability of elastic bodies with prescribed initial conditions. International Journal of Engineering Science, 4(1): 1-21. https://doi.org/10.1016/0020-7225(66)90026-7 